\title{
Analysis of the risk factors for sexual violence on women and its neurobiological aspects
}

\author{
Dutta DK', Mahanta Putul ${ }^{2}$ \\ Received (Revised) on October 30, 2018; editorial approval on April 20, 2019
}

\begin{abstract}
Sexual violence in the form of heinous offences like rapes, molestation, forced prostitution, female genital mutilations, paraphilias etc. has lately become a curse to the humanity by being one of the frequent and significant public health issue to both developed and developing countries. Being an insult to the civility, it is one of the leading causes of the severe and irreparable damage to the physical and mental health of the victims. With the development of the society the cases of sexual violence are going on increasing which is a big stigma to the mankind. Rape cases in the country have reported an increase of $12.4 \%$ from 34,651 cases in 2015 to 38,947 in 2016, the report has revealed according to the report released by National Crime Records Bureau (NCRB). Whereas according to National Family Health Survey (NFHS) an estimation of $99.1 \%$ of the sexual offences against women go unreported and these statistics shows the gravity of this curse to the society. But sadly till date nothing has been fruitfully done to prevent these offences. Interestingly extensive literatures have described that there are many factors which determine the etiologic profile of sexual violence in the society. Here in this paper the different risk factors which increases the predisposition of sexual offences is described which can be helpful in formulating the prevention strategies against the cause.
\end{abstract}

Keywords: Rape; societal norms; hypersexuality; psychiatric disorders; monoamines.

\section{INTRODUCTION}

According to WHO sexual violence is defined as: any sexual act, attempt to obtain a sexual act, unwanted sexual comments or advances, or acts to traffic, or otherwise directed, against a person's sexuality using coercion, by any person regardless of their relationship to the victim, in any setting, including but not limited to home and work. It includes a spectrum of acts including rape, molestation, incest, child sexual abuse, harassment etc. India lies in the bottom five country when comes to the safety of women as stated in Gallup poll.

\section{Factors predisposing sexual violence}

Risk factors for sexual assault are conditions, circumstances or characteristics associated with an individual or his or her environment that increase the likelihood of the individual becoming a perpetrator or a victim of sexual assault. The following risk factors are not the causes but their presence increases the risk for sexual assault.

Factors involving men's risk of committing sexual offence

WHO have demonstrated individual factors, relationship factors, community factors \& societal factors with correlation of men's propensity for sexual abuse.

\section{Individual and relationship factors}

Alcohol and drug use, coercive sexual fantasies \& other attitudes and beliefs supportive of sexual violence, impulsive and antisocial tendencies, preference for impersonal sex , hostility towards women ,history of sexual abuse as a child $\&$ witnessed family violence as a child, family environment characterized by physical violence, strongly patriarchal relationship or family environment, emotionally unsupportive family environment \& when family is honour considered more

\footnotetext{
Address for correspondence:

${ }^{1}$ MBBS Student, $5^{\text {th }}$ Semester (Corresponding author)

Tezpur Medical College, Tezpur, Assam, India

Mobile: +919678850955

Email:diptakanthadutta@gmail.com

${ }^{2}$ Professor and Head

Department of Forensic Medicine

Assam Medical College and Hospital, Dibrugarh, Assam

Mobile: +919435017802

Email: drpmahanta@gmail.com
} aspects. Int J Health Res Medico Leg Prae 2019 July;5(2):90-93. DOI 10.31741/ijhrmlp.v5.i2.2019.21 
important than the health and safety of the victim. ${ }^{1}$

\section{Societal and community factors}

Societal norms supportive of sexual violence \& of male superiority and sexual entitlement, weak laws and policies related to sexual violence, poverty, weak laws and policies related to gender equality \& prevalence of high levels of crime and other forms of violence. ${ }^{1}$

Regarding psychological factors of offenders, such men often consider victims responsible for the rape and are not keen to know the consequences to the latter. ${ }^{3}$ Victim blame was manipulated by varying the dress of the woman in the rape scenario (revealing or concealing) and the location of the rape (a library or a deserted park). On the other hand negative emotions such as disgust and guilt normally inhibit men from committing rape whereas macho attitudes adhering to a notion of masculinity that idealizes power, toughness, competitiveness, and aggression may indirectly disinhibit rape.

Moreover the constant association of pornography to sexual coercion is also evident. In a meta-analysis of 33 studies Allen et al. examined the association between pornography and nonsexual aggression by dividing sexually explicit material into three categories: (a) nudity, (b) nonviolent sexual behavior \& (c) violent sexual behavior. Overall, results indicated an association between pornography and aggression. However, type of pornography was a moderator, such that exposure to nudity decreased aggression, whereas exposure to the latter two categories significantly increased aggression. ${ }^{4}$

A normal man is not aroused by a scene of sexual violence against a woman but certain circumstances like being angry at the women can alter that and can result to the arousals similar that of rapists. There was noticed a $50 \%$ decrease in blood flow by penile plethysmograph to the normal man's genital in response to scenes of rape or violence but it was not noticed in the case of the rape offenders instead their arousal was markedly stronger to the rape scene than to consenting sex. ${ }^{12}$

\section{Factors related to women}

Though the victims are never responsible for the sexual violence against them but certain factors are seen to be constantly related which increases their vulnerability. Other factorsinfluencing the risk of sexual violence include: being young, consuming al cohol or drugs, having previously been raped or sexually abused, having many sexual partners, involvement in sex work, becoming more educated and economically empowered at least where sexual violence perpetrated by an intimate partner is concerned \& poverty. ${ }^{1}$ Consuming alcohol or drugs makes it more difficult for women to protect themselves by interpreting and effectively acting on warning signs so can place them in higher risks for encountering offence. A study found that women who had experienced attempted or completed rape during childhood or adolescence were more likely to have a higher number of sexual partners in adulthood, compared with non-abused or moderately abused women, increasing their predisposition to rape. ${ }^{5}$ Interestingly women with higher levels of education is more likely to experience sexual violence than rest as found in a national survey in South Africa. It maybe because empowerment brings with it more resistance from women to patriarchal norms so that men apply violence in order to regain the control resulting in the offence.

\section{Role of mental health}

The underlying causes of certain sexual offences are the altered state of mental health \& can be associated with organic brain damage, disorders with congenital or acquired brain damage, head injuries $(3.9 \%)^{6}$ and abnormalities within the temporal horn as in sadist rapist. ${ }^{7}$ It has been found that in certain psychiatric diseases like schizophrenia, there is a four fold chances of committing sexual offences and bipolar mood disorder especially in the maniac phase. ${ }^{8}$ Other symptoms such as the increase of self-esteem, feelings of grandiosity, grandiosity delusions, considering oneself to be a special person, endowed with powers and high intelligence frequently present along with increase in the motor activity showing great physical vigour relating to the cause of offence. ${ }^{9}$ Langstrom et al in their retrospective study on 535 rape offenders found the incidence of psychiatric background as the diagnoses were alcohol abuse or dependence $(9.3 \%)$, drug abuse $(3.9 \%)$, personality disorder $(2.6 \%)$, and psychosis $(1.7 \%)^{10}$ According to DSM-IV sexual offenses against children are mainly by individuals with paraphilias like Exhibitionism, Pedophilia, and Voyeurism. ${ }^{11}$

\section{Understanding the neuronal level in case of hypersexuality}

It is always very much important for understanding the neurobiology of the hypersexuality to know the causes of these violences. By hypersexual disorder, it encompasses sexual addiction and compulsive sexual behaviors involving the activation of neurotransmitters such as noradrenaline (NE) and oxytocin (OT), stimulating sexual arousal, and dopamine (DA) and melanocortins (MCs), stimulating attention and desire, within regions of the hypothalamus and limbic system, in response to sexual cues and stimulation. Their activation blunts the influence of inhibitory mechanisms, such as endogenous opioids, which are released in the cortex, limbic system, hypothalamus, and midbrain during an orgasm or sexual reward; endocannabinoids (ECBs), which mediate sedation; and serotonin (5-HT), which is released in those regions to induce refractoriness and sexual satiety. Sexual excitation can be primed internally by steroid hormone actions or externally by sexual incentives or drugs that activate excitatory neurochemical systems. ${ }^{2}$ Any overexpression of these pathways can lead to hypersexuality like disorders.

In a recent survey with pedophillic patients, Mendez and Shapira demonstrated that brain disorders may trigger a predisposition to sexual attraction towards children through disinhibition and sexual preoccupation ${ }^{20}$ as in cases of diseases of frontal lobe, striatum, temporo-limbic system and hypothalamus. Frontal lesions maybe accompanied by general disinhibition, including impulsive hypersexual symptoms; striatal lesions by increased in the triggering of sexual 
response patterns and temporo-limbic lesions by disturbances in sexual appetite itself including the change in the sexual life. ${ }^{13}$ Hypersexuality was found to be associated with subcortical disease in nonmotor basal ganglia, hypothalamus, or septal nuclei ${ }^{20}$ and also in dementia, temporal lobe epilepsy and patients with frontal lobotomy. ${ }^{21}$ Further ABC model (Stein, 2008) hypothesized the possible model for hypersexual behavior by stating that the Amygdala leads to affective dysregulation, Behavioral reward is controlled by the nucleus accumbens, where the concentration of the dopamine is seen to enhanced and ventral striatal circuits, and Cognitive control is impaired in the prefrontal cortex. ${ }^{14}$

\section{Endocrinology}

The role of monoamines like serotonin (5-HT) and Dopamine(DA) has also been elicited in mediating the hypersexuality. 5-HT is involved in many psychiatric disorders, particularly mood disorder, and specifically depression, anxiety, schizophrenia, eating disorders, and obsessive compulsive disorder (OCD). ${ }^{16}$ Stein et al have demonstrated the role of DA blocker and 5-HT reuptake inhibitor in controlling the hypersexual behavior. Increasing brain levels of 5-HT reduced sexual drive and sexual behavior and decrease showed opposite. Therefore drugs that increase 5-HT levels in the brain have been used to treat paraphilias. ${ }^{15}$ Moreover Klos et al has been demonstrated that antiparkinsonism drugs which increases the DA level in the brain are related to hypersexual disorder, ${ }^{17}$ which strengthens association the DA theory. Ristow et al(2018) has shown the reduced concentration of GABA in the dorsal anterior cingulate cortex in the cases of pedophilic offenders which demonstrates the role of GABA in treating hypersexuality. ${ }_{-}^{18}$

Some studies have stated that violent sex offenders have higher levels of androgens than nonviolent comparison groups correlating with sexual offences. ${ }^{22}$ Thus testosterone has been shown to be related to the hypersexuality mainly the free testosterone, but few researches have also predicted that $\mathrm{LH}$ correlated significantly with sexual and violent recidivism ${ }^{19}$ and thus the role of hypothalamo-pituitary-gonadal dysfunction also come into play. Meanwhile in a study with pedophilic men, Maes et al. found lower plasma Prolactin (PRL) levels in the pedophiles than in the controls. ${ }^{23}$ PL has been seemed to play a negative feedback loop to modify the effects of the dopaminergic systems. The treatment of hypersexuality related disorders with SSSRIs, Antiandrogens $\& \mathrm{GnRH}$ analogues is also noteworthy. SSRIs like fluoxetine increase serotonin levels by blocking the uptake of serotonin to its presynaptic neurons and increasing its concentration. Antiandrogens like cyproterone acetate (CPA) directly reduces the testosterone levels. GnRH analogue like Triptorelin decreases pituitary secretion of the gonadotrophins luteinising hormone (LH) and follicle stimulating hormone (FSH). This in turn inhibits the production of testosterone by the testes.

\section{CONCLUSION}

Different literatures have shown that there are certain determinants reflecting the risk factors for sexual offences and by eliminating these factors the incidence of such offences can be minimized manifold. Factors starting from the individual, societal to neuronal level; all can be to a certain level treated and prevented. Proper study must be encouraged regarding the detailed description of the underlying events regarding the etiology of sexual offences. Moreover by considering the above risk factors the urge of formulation of the preventive strategies for these offences must be promoted.

Conflict of interest: None declared.

\section{Source of funding: None. \\ REFERENCES}

1. Sexual violence. In: E.G. Krug, L.L. Dahlberg, J.A. Mercy, et al. editors. World report on violence and health. Geneva, World Health Organization. 2002. p. 147-81.

2. Pfaus JG. Pathways of sexual desire. J Sex Med 2009;6:1506-33.

3. Drieschner K, Lange A. A review of cognitive factors in the aetiology of rape: theories, empirical studies and implications. Clinical Psychology Review 1999;19:5777.

4. Allen M, D’Alessio D, Brezgel K. A meta-analysis summarizing the effects of pornography II: Aggression after exposure. Hum Commun Res 1995;22:258-83.

5. Olsson A. Sexual abuse during childhood and adolescence among Nicaraguan men and women: a population-based survey. Child Abuse \& Neglect 2000;24:1579-89.

6. Langstrom N, Sjostedt G, Grann M. Psychiatric disorders and recidivism in sexual offenders. Sex Abuse. 2004 Apr;16(2):139-50.

7. Aigner M, Eher R, Fruehwald S, Frottier P, GattirezLobos K, Dwyer S. Brain abnormalities and violent behaviour. J Psychol Human Sex 2000;11:57-64.

8. Drake CR, Pathe M. Understanding sexual offending in schizophrenia. Crim Behav Ment Health 2004; 14:10820.

9. Valenca AM, Nascimento Isabella, Nardi Antonio Egidio. Relationship between sexual offences and mental and developmental disorders: a review. Rev psiquiatr clin [serial online] 2013 [cited 2019 Jan 09]; 40(3):[97-104]. Available from: URL:http:// w w w.s c i e lo.br/s c i e lo.ph p ? s r i p t $=$ sci_arttext\&pid=S0101-60832013000300004\&lng=en.

10. Langstrom N, Sjostedt G, Grann M. Psychiatric disorders and recidividsm in sexual offenders. Sex Abuse 2004;16:139-50.

11. American Psychiatric Association: Diagnostic and Statistical Manual of Mental Disorders. Washinghton DC: American Psychiatric Association; 1994.

12. Goleman D. New Studies Map the Mind of the Rapist. The New York Times [serial online] 1991 December 10; Available from: URL: $\underline{\text { https:// }}$ 
www.nytimes.com/1991/12/10/science/new-studiesmap-the-mind-of-the-rapist.html

13. Stein DJ, Hugo F, Oosthuizen P, Hawkridge SM, Van Heerden B. Neuropsychiatry of hypersexuality. CNS Spec trums 2000;5:36-46.

14. Samenow, Charles P. A Biopsychosocial Model of Hypersexual Disorder/Sexual Addiction. Sexual Addiction \& Compulsivity 2010;17(2):69-81.

15. Brad ford JMW. Pharmacological treatment of the paraphilias. Review of Psychiatry 1995;14:755-78.

16. Bradford JM. The neurobiology, neuropharmacology and pharmacological treatment of the paraphilias and compulsive sexual behaviour. Can J Psychiatry 2001;46:26-34.

17. Klos K, Bower J, Josephs K. Pathological hypersexuality predominantly linked to adjuvant dopamine agonist therapy in Parkinson's disease and multiple system atrophy. Parkinsonism \& Related Disorder 2005;11(6):381-6.

18. Inka Ristow, Meng Li, Lejla Colic. Pedophilic sex offenders are characterised by reduced GABA concentration in dorsal anterior cingulate cortex. Elsevier NeuroImage: Clinical 2018;18:335-41.

19. Drew AK, Michael CS, Adekunle GA. The Role of Central and Peripheral Hormones in Sexual and Violent Recidivism in Sex Offenders. Journal of the American Academy of Psychiatry and the Law Online Dec 2012;40(4):476-85.

20. Mendez M, Shapira JS. Pedophilic behavior from brain disease. J Sex Med 2011;8:1092-100.

21. Kaplan MS, Krueger RB. Diagnosis, assessment, and treatment of hypersexuality. J Sex Res 2010;47:18198.

22. Brooks J, Reddon J. Serum testosterone in violent and nonviolent young offenders. J Clin Psychol 1996;52:475-83.

23. Maes M, VanWest D, De Vos N, Westenberg H, Van Hunsel F, Hendriks D, et al. Lower baseline plasma cortisol and prolactin together with increased body temperature and higher mCPP-induced cortisol responses in men with pedophilia. Neuropsychopharmacology 2001;24:37-46. 
